\title{
New Methods of Monitoring Shock in Children
}

\section{Helen Turnham, MBChB (HONS) FRCA Joe Brierley, MBChB, FRCPCH*}

\author{
Address \\ *Paediatric Intensive Care, Great Ormond Street Hospital, London, WC1N 3JH, UK \\ Email: Joe.brierley@GOSH.nhs.uk
}

Published online: 22 January 2015

(C) Springer International Publishing AG 2015

This article is part of the Topical Collection on Pediatric Critical Care Medicine

Keywords Paediatrics - Critical care - Shock - Cardiac output - Organ perfusion - Goal-directed therapy Cardiovascular monitoring

\section{Opinion statement}

Shock in children is a cause of significant morbidity and mortality. Worldwide, most children dying from shock do not have the opportunity to benefit from advanced critical care support and we recommend to readers the World Health Organization ETAT guidelines [1]. For children treated in the intensive care environment, standard cardiovascular measures such as heart rate, pulse volume, perfusion/capillary refill, core-peripheral temperature gradient and blood pressure along with measures from other organ systems (e.g. urine output and consciousness level) remain vital. All are part of the global assessment of cardiovascular performance and shock in children, and none of the new techniques we describe replace the need for these assessments in critically ill children. Furthermore, evidence is lacking to mandate utilisation of any of the advanced methods we review and they should only be considered as adjuncts to the aforementioned assessments in critical care. We suggest that the optimal monitoring of the shocked child in the ICU, and those developing shock outside the ICU, should include measuring those hemodynamic parameters above together with assessment of preload responsiveness and organ perfusion. Early goal-directed therapy targeting shock reversal remains the consensus best practice position and includes optimization of several haemodynamic parameters [2]. Our personal practice remains to firstly target clearance of raised lactate and venous desaturation, measured by intermittent blood gas analysis and secondly to optimise preload, contractility and afterload guided by Doppler ultrasound or echocardiography. Both can be undertaken in both the emergency department as well as the ICU.

\section{Introduction}

Shock can be defined simply as failure to deliver oxygen to, and remove metabolites from, sites of cellular respiration. This leads to the development of an oxygen deficit and if untreated can lead to organ failure and death. Sepsis is a common cause of shock in children leading to alterations in vascular tone, cardiac 
contractility and volume status. The American College of Critical Care Medicine (ACCM) consensus guidelines recommend time-sensitive rapid shock reversal as best practice [2].

Children in septic shock have been described as presenting with two distinct clinical pictures: high cardiac output with low systemic vascular resistance and low cardiac output with high systemic vascular resistance, so-called warm and cold shock, respectively [3]. Unlike the case in many adults with shock, these states are not fixed and children may move between them during treatment [ $4 \bullet]$. Standard monitoring techniques such as heart rate, blood pressure and capillary refill time can fail to detect these shifts in hemodynamic status. They may also underestimate oxygen deficit and perform poorly as markers of circulatory failure [5]. Clinical examination alone is inaccurate [6], and the failure of standard monitoring techniques to differentiate between warm and cold shock can hinder optimisation of cellular perfusion.

An increasing number of novel measuring techniques are emerging into paediatric practice. Unfortunately, studies into cardiovascular monitors in children are almost entirely single-centre studies, with small numbers of patients (fewer than 50) and have often been conducted under steady-state conditions rather than during haemodynamic instability.

\section{Measures of hemodynamics}

Blood pressure (BP) is a product of cardiac output and systemic vascular resistance $(\mathrm{SVR})$. Cardiac output $(\mathrm{CO})=$ heart rate $\times$ stoke volume. Stoke volume depends on preload, contractility and afterload.

Unfortunately, trinomial equations cannot estimate variables in a dynamic state, ergo blood pressure monitoring alone cannot define adequate cardiac output (flow).

The American College of Critical Care Medicine (ACCM) advocates targeting cardiac index $(\mathrm{CI}=\mathrm{CO} /$ body surface area $)$ of $3.3-6.0 \mathrm{~L} / \mathrm{min} / \mathrm{m}^{2}$ in children with catecholamine-resistant septic shock. In children, low CI rather than low SVR, particularly in septic shock, is associated with increased mortality [7].

Initial attempts to measure invasive hemodynamics in the critical care units of the 1970s focussed on use of the pulmonary artery catheter (PAC) [8] and exploitation of the Fick principle: total uptake or release of a substance (oxygen, carbon dioxide, dye or heat) is equal to blood flow (CO) to the organ and the arteriovenous concentration difference of the substrate [9]. This technique, and many others, is based upon the traditional catheter laboratory experiments and is the gold standard to which new hemodynamic monitors are compared [10]. However, PAC use in adults-let alone children-is controversial with safety concerns and limited availability of trained staff to place and manage PAC delaying data acquisition [11, 12]

\section{Transpulmonary indicator dilution techniques}

Transpulmonary indicator dilution (TPID) techniques involve injection of an indicator substance (heat or lithium) into a central venous line, and indicator concentration is measured at a large peripheral artery. The Stewart Hamilton equation describes calculation of an unknown volume (e.g. stroke volume) from a known mass of marker and its concentration over time (stroke volume $(\mathrm{SV})=$ mass/concentration). 
Concentration is the area under the curve (AUC) of a concentration/time graph with CO inversely proportional to the AUC. Two TPID techniques have been validated in children, thermodilution (PiCCO) [13-16] and lithium dilution (LiDCO) [17]. Avoiding pulmonary artery cannulation prevents complications such as line knotting in the tricuspid valve apparatus or pulmonary artery injury, but these newer techniques still require cannulation of a central vein and artery. Prolonged femoral artery cannulation with large calibre cannulae, although a common procedure in ICU, has significant risks [12]. Like PAC, TPID can only deliver intermittent hemodynamic estimations limiting its usefulness in situations of rapidly changing cardiovascular status. Both LiDCO and PiCCO overcome this limitation by incorporating a continuous measurement technique based upon arterial pulse pressure waveform analysis to estimate stroke volume.

\section{Pulse pressure waveform analysis}

In arteries, fluctuations in pressure around the MAP are a consequence of the volume of blood ejected into the artery during systole (SV). Pulse pressure is a function in magnitude of stroke volume [18]. Stroke volume estimations can therefore be made from pulse pressure wave (PPW) analysis-though we have expressed reservations ourselves about this technique [19].

Monitors that examine the PPW can be divided into those that analyse pulse contour morphology (PiCCO and LiDCO) and those that measure pulse power (LiDCO rapid and FloTrac) or pressure-time area's (pressure recording analytical method, PRAM). Measures of pulse contour calculate area under the systolic portion of the PPW and require regular calibration by another technique because arterial compliance and vascular resistance alter with pressure changes. Pulse power/pulse time measures such as LiDCO rapid, FloTrac and PRAM analyse both the systolic and diastolic portions of the PPW; they are not calibrated as the computational algorithms include compensation for arterial compliance changes with pressure. In adults, PPW analysis is a good surrogate for SV, but over time, changes in vascular tone reduces reliability [20]. An advantage for children of this technique is that PPW can be analysed from any in situ arterial line, reducing interventions. To date, studies to validate precision and accuracy of PPW monitors in children have been varied. PiCCO is validated for TPID but not pulse contour analysis $[11,21]$. FloTrac failed to validate against PAC thermodilution [22]. PRAM failed to validate well against transpulmonary ultrasound dilution with the authors recommending that the current PRAM algorithm is not used in critically ill children [23]. The LiDCO algorithm has been validated in children, though the small study did not include those under $13 \mathrm{~kg}$ [24]. Understanding the limitations of these devices, summarised in Table 1, to give accurate data, PPW analysis can still be a useful guide of trends in CO.

Techniques to measure $\mathrm{CO}$ in children that rely upon insertion of invasive lines require skilled practitioners, and insertion can delay therapy. They have a place in ICU-especially if giving continuous readings, but utility is limited by cost, need for expertise, accuracy concerns and potential harm to patients. We suggest technologies that are easy to use and with good reproducibility that do not require specialist procedural skills are the future for paediatric goal-directed management of shock. 


\begin{tabular}{|c|c|c|c|}
\hline & Pulse contour analysis & Pulse power analysis & Pressure time analysis \\
\hline Market example & PiCCO & LiDCO rapid & PRAM \\
\hline Arterial access & $\begin{array}{l}\text { Specialised line, long length for central } \\
\text { placement, large artery }\end{array}$ & $\begin{array}{l}\text { Any arterial cannula in } \\
\text { any artery }\end{array}$ & $\begin{array}{l}\text { Any arterial cannula in } \\
\text { any artery }\end{array}$ \\
\hline Waveform accuracy & $\begin{array}{l}\text { Need good arterial pressure trace with } \\
\text { clear dicrotic notch }\end{array}$ & $\begin{array}{l}\text { Any arterial waveform, } \\
\text { even damped traces }\end{array}$ & $\begin{array}{l}\text { Any arterial waveform, } \\
\text { even damped traces }\end{array}$ \\
\hline Calibrated & Yes & No & No \\
\hline $\begin{array}{l}\text { Validated PPW } \\
\text { analysis in children }\end{array}$ & No & Partial & No \\
\hline
\end{tabular}

\section{Partial carbon dioxide rebreathing indirect Fick}

A non-invasive method of measuring $\mathrm{CO}$ exploiting the Fick principle, as described above, using carbon dioxide $\left(\mathrm{CO}_{2}\right)$ as the indicator has been developed. The partial pressure of end tidal $\mathrm{CO}_{2}\left(\mathrm{PETCO}_{2}\right)$ is measured at the tracheal tube. $\mathrm{PETCO}_{2}$ during normal ventilation approximates the arterial content of $\mathrm{CO}_{2}$ and $\mathrm{PETCO}_{2}$ during a partial rebreathing exercise approximates mixed venous content of $\mathrm{CO}_{2}$. The technique has been evaluated in children in a single small study, but only in children over the weight of $15 \mathrm{~kg}$ and those who are mechanically ventilated, limiting its use [25].

\section{Doppler phenomenon}

Exploitation of the Doppler phenomenon is an alternative method of CO monitoring that avoids cannulation of vessels and does not require intubation. Alterations in the frequency of transmitted sound waves as they are reflected from moving objects (e.g. blood cells) can be used to measure flow velocity across heart valves and vessels. These are no new techniques, but specific new devices have been investigated in children in recent years such as ultrasonic cardiac output monitor (USCOM) and cardioQP.

USCOM uses continuous-wave (CW) Doppler via a probe to produce velocity-time graphs of the high velocity flows across either the aortic or pulmonary valves. Estimations of valve diameter are made using an algorithm based on height, weight and gender [26] with hemodynamic data provided by automated calculations of velocity-time integral (distance travelled by a column of blood over a fixed time) to calculate stroke volume. Studies have suggested reliability for both physicians and non-physicians following a short training period with both good inter- and intra-user reliability $[27,28]$. USCOM can be used in children outside ICU [29] permitting earlier hemodynamic information than traditionally available.

Comparing USCOM to PAC thermodilution demonstrated a $36 \%$ mean error, falling outside acceptable criteria for device precision [30]. However, this methodology has itself been challenged and USCOM precision is comparable 
to other non-invasive $\mathrm{CO}$ measurement techniques [17]. The precision of PAC itself is increasingly being questioned [31].

USCOM has been compared to echocardiography Doppler measures, 'estimated' (USCOM) and 'measured' left ventricular outflow tract diameters were not significantly different, but USCOM consistently 'overestimated' CO, particularly in children with septic shock [29]. It has been suggested this might be related to CW Doppler use which measures the highest velocity profile as opposed to pulsed-wave (PW) Doppler used in echocardiography where the user directs the Doppler beam [32]. Whilst some suggest limitations to achieving precise CO measurements with USCOM, multiple studies have used the technique to guide therapy in children suggesting USCOM can predict fluid responsiveness in shock [33] and track the evolution of sepsis in children managed in ICU $[2,34]$. On-going USCOM studies are investigating potential cardiac inotropy measures but are not reported in children [35].

Oesophageal Doppler (CardioQP, Deltex) similarly directly measures flow, albeit in the descending aorta with a patient-specific inserted disposable probe. However, descending aorta pulsatility is of concern for accurate cross-section area calculation [36].

\section{Transthoracic echocardiography}

Transthoracic echocardiography (TTE) has appeal for monitoring hemodynamics in children with shock. Preload can be assessed using inferior vena cava diameter, discussed later, or by measuring end-diastolic left ventricular parameters. SV estimations can be made using PW Doppler directed across the left or right ventricular outflow tracts. More recently, dynamic global cardiac performance indices such as myocardial performance index have been developed. Transthoracic echocardiography traditionally required expert operators but recently 'targeted bedside echocardiography' by non-physicians has been suggested to be an effective technique for monitoring shock in children [37, 38].

\section{Bioreactance}

Several non-invasive techniques that require minimal training have recently been introduced into paediatric practice. Routine application of electrical velocimetry was compromised by electrical interference; however, bioreactance overcomes this by analysing phase shifts rather than signal change. A highfrequency $(75 \mathrm{~Hz})$ oscillating current is passed externally across the chest via four electrode stickers which also detect phase shifts in the current. Intra-aortic blood volume changes during the cardiac cycle are the primary source of phase shifts and can be analysed mathematically to estimate stroke volume. Comparison with PAC thermodilution, however, during cardiac catheterisation noted persistent over- and underestimation of cardiac output [39]. Comparing bioreactance estimation of $\mathrm{CO}$ to transthoracic echocardiogram in neonates with patent ductus arteriosus [40], paediatric cardiac patients [41] and paediatric neurosurgical patients [42], NICOM persistently underestimated SV. Studies in children have only been conducted in surgical patients, and comparison of bioreactance to thermodilution via PAC in critically ill adults with a variety of underlying pathologies also demonstrated poor correlation in values 
[43]. In an animal model of paediatric haemorrhagic shock, again bioreactance consistently underestimated cardiac index [44].

Preload assessment

\section{Perfusion and tissue oxygenation}

Fundamentally, shock is the failure to deliver adequate oxygen to organs. This leads to increased extraction of oxygen from blood which reduces mixed venous oxygen saturations $\left(\mathrm{SvO}_{2}\right)$; therefore, $\mathrm{SvO}_{2}$ is an indirect measure of oxygen delivery but requires sampling of blood from the pulmonary artery. In the absence of indwelling PACs, sampling of blood from the superior vena cava (central venous oxygen saturations, $\mathrm{ScvO}_{2}$ ) has been shown to be a suitable surrogate [51]. Children are more likely to suffer from shock with low cardiac output than adults and to have lower ScvO2 [52]. Two recent studies of children with shock, albeit with relatively high background mortality, demonstrated that directing treatment to achieve a $\mathrm{ScvO}_{2}$ greater than $70 \%$ significantly reduced mortality, with a number needed to treat between 3.6 and $6[53,54]$. Standard therapy was augmented in the intervention groups by a number of measures to improve shock, as quantified by venous desaturation, such as fluids, inotropes and transfusion. This parallels the landmark study by Rivers et al. recommending early goal-directed therapy in septic adults $[55,56,57 \bullet]$.

\section{Continuous measure of $\mathrm{ScvO}_{2}$}

PediaSat, a central venous catheter with in-line oximetry allowing continuous $\mathrm{ScvO}_{2}$ measurement, has been developed to enable continuous targeting of venous desaturation in paediatric shock. Two studies in critically ill children 
suggested that PediaSat accurately measured $\mathrm{ScvO}_{2}[58,59]$, but two separate studies in surgical patients $[60,61]$ failed to demonstrate accurate correlation with laboratory samples of $\mathrm{ScvO}_{2}$. Like other devices discussed, PediaSat is an invasive monitor, reducing its early application in shocked children.

\section{Near-infrared spectroscopy}

Serum markers of globally poor perfusion such as lactate and base deficit are indirect and often late signs of poor organ perfusion in children who are in shock. Although lactate clearance has been shown to be a useful target for shock reversal therapies in adults and children. An alternative to non-specific global measures are methods of monitoring regional oxygenation.

Oxyhaemoglobin and deoxyhaemoglobin absorb light in the infrared region at different wavelengths. Passing infrared light through tissues and measuring relative absorptions permit estimation of haemoglobin saturation, known as regional saturation $\left(\mathrm{rSO}_{2}\right)$. This non-pulsatile signal is primarily a measure of capillary venous saturation, related but not equal to $\mathrm{ScvO}_{2}$. Spatial resolution ensures that only deep tissue oxygenation is considered. Nearinfrared spectroscopy (NIRS) is a continuous monitor of regional oxygenation. NIRS devices can monitor $\mathrm{rSO}_{2}$ in cerebral, renal, mesentery and peripheral muscle circulations, as current devices have a field depth of 1-4 cm; multisite technology is most suitable in children under $10 \mathrm{~kg}$.

Cerebral NIRS monitoring during and following cardiac surgery has been extensively discussed with some suggesting it ought to be a standard of care [62] though we cannot find outcome data to support widespread introduction in ICU. Multisite NIRS can theoretically measure regional and global organ perfusion in shock, but use is limited by the absence of a proven normal baseline $\mathrm{rSO}_{2}$ and what might constitute a significant reduction. In addition, there are significant device and consumables costs. A reduction of $20 \%$ from a suggested normal baseline $\mathrm{rSO}_{2}$ of $70 \%$ has been shown to predict risk of organ injury [63], but few studies have investigated the utility of multisite NIRS in shocked children. One small study suggests that average cerebral and renal $\mathrm{rSO}_{2}$ of less than $65 \%$ correlates with elevations in serum lactate-a marker of globally poor perfusion [64]. Whilst NIRS is non-invasive and does not require extensive specialist training, further studies are required before its use in any paediatric population.

\section{Conclusion}

Shock is a cause of significant mortality and morbidity in children, and early goal-directed therapy of shock states has been shown to improve outcomes with measures of hemodynamics, preload and tissue oxygenation successfully guiding therapy in paediatrics. Despite many years of development, no single measure of 'invasive hemodynamic performance' has been widely accepted in paediatric critical care practice. Whilst each technique has advantages and disadvantages, preference surely ought to be given to systems that can measure hemodynamics accurately, non-invasively, reproducibly and safely.

As early goal therapy with hemodynamic optimisation remains recommended treatment in paediatric shock, our personal practice remains targeting 
of clearance of raised lactate and venous desaturation, measured by intermittent blood gas analysis, using optimisation of preload, contractility and afterload guided by Doppler ultrasound or echocardiography which can be undertaken in both the emergency department as well as the ICU.

\section{Compliance with Ethics Guidelines}

\section{Conflict of Interest \\ Helen Turnham and Joe Brierley declare that they have no conflict of interest.}

\section{Human and Animal Rights and Informed Consent}

This article does not contain any studies with human or animal subjects performed by any of the authors.

\section{References and Recommended Reading}

Papers of particular interest, published recently, have been highlighted as:

- Of importance

1. World Health Organization ETAT guidelines. Available at: http://whqlibdoc.who.int/publications/2005/ 9241546875_eng.pdf?ua=1. (accessed 09/14)

2. Brierley J, Carcillo J et al. Clinical practice parameters for hemodynamic support of pediatric and neonatal septic shock: 2007 update from the American College of Critical Care Medicine, Crit Care Med. 2009 Vol. 37, No. 2.

3. Brierley J, Peters MJ. Distinct hemodynamic patterns of septic shock at presentation to pediatric intensive care. Pediatrics. 2008;122(4):752-9.

4. Deep A, Goonasekera CDA, Wang Y, Brierley J. Evolution of haemodynamics and outcome of fluidrefractory septic shock in children. Sept 2013; 39(9):1602-1609.

The study demonstrated that type of shock (high CI with low SVR versus low CI with high SVR) optimising cellular perfusion requires monitoring of haemodynamics to titrate therapy

5. Scott JP, Hoffman GM. Near-infrared spectroscopy: exposing the dark (venous) side of the circulation. Paediatr Anaesth. 2014;24(1):74-88.

6. Tibby SM, Hatherill M, Marsh MJ, et al. Clinicians' abilities to estimate cardiac index in ventilated children and infants. Arch Dis Child. 1997;77:516-8.

7. Mercier JC et al. Hemodynamic patterns of meningococcal shock in children. Crit Care Med. 1988;16:27.

8. Swan H, Ganz W, Forrester J, et al. Catheterisation of the heart in man with use of a flow directed balloon tipped catheter. N Engl J Med. 1970;27:392-6.

9. Cross M, Plunkett E. Physics, pharmacology and physiology for anaesthetists: key concepts for the FRCA. 1st ed. Cambridge: Cambridge University Press; 2008.
10. Theile RH, Bartels K, Gan TJ. 'Cardiac output monitoring: a contemporary assessment and review' Critical Care Medicine. Sept 2014.

11. Perkin R, Anas N. 'Pulmonary artery catheter' Paediatric intensive care medicine. 2011 No 4 Suppl S12-20.

12. Lemson J, Nusmeier A, van der Hoeven JG, Lehman R, Ceccheti $\mathrm{C}$. The pulmonary artery catheter in the pediatric intensive care unit: not the way to go. Pediatr Crit Care Med. 2012;13(2):250-1.

13. Proulx F, Lemson J, Choker G, Tibby SM. Hemodynamic monitoring by transpulmonary thermodilution and pulse contour analysis in critically ill children. Pediatr Crit Care Med. 2011;12(4):459-66.

14. McLuckie A, Murdoch IA, Marsh MJ, et al. A comparison of pulmonary and femoral artery thermodilution cardiac indices in paediatric intensive care patients. Acta Paediatr. 1996;85:336-8.

15. Tibby SM, Hatherill M, Marsh MJ, et al. Clinical validation of cardiac output measurements using femoral artery thermodilution with direct Fick in ventilated children and infants. Intensive Care Med. 1997;23:987-91.

16. Pauli C, Fakler U, Genz T, et al. Cardiac output determination in children: equivalence of the transpulmonary thermodilution method to the direct Fick principle. Intensive Care Med. 2002;28:947-52.

17. Linton RA, Jonas MM, Tibby SM, Murdoch IA, O'Brien TK, Linton NW, et al. Cardiac output measured by lithium dilution and transpulmonary thermodilution in patients in a paediatric intensive care unit. Intensive Care Med. 2000;26(10):1507-11. 
18. Pinsky MR, Payen D. Functional hemodynamic monitoring, update in intensive care and emergency medicine. 2005; 42, pp 183-192 Springer-Verlag Berlin Heidelberg.

19. Phillips R, Brierley J. Fluid responsiveness is about stroke volume, and not pulse pressure Yogi: the power of Doppler fluid management and cardiovascular monitoring. J Clin Monit Comput. 2014 Jul 22.

20. Cecconi M, Rhodes A. Pulse pressure analysis: to make a long story short. Crit Care. 2010;14:175.

21. Kutter AP, Bektas RN, Hofer CK, Larenza Menzies MP, Bettschart-Wolfensberger R. Trending ability and limitations of transpulmonary thermodilution and pulse contour cardiac output measurement in cats as a model for pediatric patients, J Clin Monit Comput. 2014 Sep 17 e publication ahead of print.

22. Teng S, Kaufman J, Pan Z, et al. Continuous arterial pressure waveform monitoring in paediatric cardiac transplant, cardiomyopathy and pulmonary hypertension patients. Intensive Care Med.

2011;37:1297-301.

23. Saxena R, Durward A, Puppala NK, Murdoch IA, Tibby SM. Pressure recording analytical method for measuring cardiac output in critically ill children: a validation study. Br J Anaesth. 2013;110(3):425-31.

24. Kim JJ, Dreyer J, Chang A, et al. Arterial pulse wave analysis: an accurate means of determining cardiac output in children. Pediatr Crit Care Med.

2006;7(6):532-5.

25. Botte A, Leclerc F, Riou Y, Ahmed S, Neve V, Rakza T, et al. Evaluation of a noninvasive cardiac output monitor in mechanically ventilated children. Paediatr Crit Care Med. 2006;7(3):231-6.

26. Knirsch W, Kretschmar O et al. Cardiac output measurement in children: comparison of the ultrasound cardiac output monitor with thermodilution cardiac output measurement' Intensive Care Medicine, Jan 2008 Vol... p.

27. Chong SW, Peyton P. A meta-analysis of the accuracy and precision of the ultrasonic cardiac output monitor (USCOM). Anaesthesia. 2012;67:1266-71.

28. Dhanani S, Barrowman NJ, Ward RE, Murto KT. Intra and inter-observer reliability using a noninvasive ultrasound cardiac output monitor in healthy anaesthetised children. Paediatr Anaesth. 2011;21(8):858-64.

29. Zorko DJ, Choong K, Gillelans J, et al. Urgent ultrasound guided haemodynamic assessments by a pediatric medical emergency team: a pilot study. PLoS ONE. 2013;8(6):e66951.

30. Knirsch W, Kretschmar O, Tomaske M, et al. Cardiac output measurement in children: comparison of the ultrasound cardiac output monitor with

thermodilution cardiac output measurement. Intensive Care Med. 2008;34(6):1060-4.

31. Phillips R, Hood S, Jacobson B, West M, Wan L, May C. Pulmonary artery catheter (PAC) accuracy and efficacy compared with flow probe and transcutaneous doppler (USCOM): an ovine cardiac output validation.
Critical Care Research and Practice. 2012; Article ID 621496, 9 pages

32. Wondsirimetheekul $\mathrm{T}$, Khositseth A, Lertbunrian R. Non-invasive cardiac output assessment in critically ill paediatric patients. Acta Cardiol. 2014;69(2):167-73.

33. Wu Y, Lui X, He Y, et al. Clinical observations of noninvasive ultrasonic cardiac output monitor combined with passive leg raising in predicting the children volume responsiveness. Chin Crit Care Med. 2014;26(1):46-50.

34. Cai HB, Song P, Zhang $\mathrm{L}$, et al. Clinical application of cardiac output monitoring in children with severe hand-foot-mouth disease. Chin J Contemp Paediatr. 2012;14(4):271-5.

35. Smith BE, Madigan VM. Non-invasive method for rapid bedside estimation of inotropy: theory and preliminary clinical validation. Br J Anaesth.

2013;111(4):500-8.

36. Working Group on Non-invasive Haemodynamic Monitoring in Paediatrics, Knirsch W, Kretschmar O, Tomaske M, Stutz K, Nagdyman N, et al. Comparison of cardiac output measurement using the CardioQP oesophageal Doppler with cardiac output measurement using thermodilution technique in children during heart catheterisation. Anaesthesia.

2008;63(8):851-5.

37. Gaspar HA, Morhy SS, Lianza AC, et al. Focused cardiac ultrasound: a training course for pediatric intensivists and emergency physicians. BMC Med Educ.

2014;14:25.

38. Ranjit S, Aram G, Kissoon N, Ali MK, Natraj R, Shresti S, et al. Multimodal monitoring for hemodynamic categorization and management of pediatric septic shock: a pilot observational study. Pediatr Crit Care Med. 2014;15(1):e17-26.

39. Van Aelst E. Cardiac output measurement in children: comparison of a non invasive bioreactance based system and thermodilution.

40. Weisz DE, Jain A, Ting J, McNamara PJ, El-Khuffash A. Non-invasive cardiac output monitoring in preterm infants undergoing patent ductus arteriosus ligation: a comparison with echocardiography. Neonatol. 2014;106(4):330-6.

41. Sun Y1, Wu C, Wu JZ, Wang SS, Bai J, Zhu M, Zhang YQ, Zhang MZ. Noninvasive cardiac output monitoring using bioreactance-based technique in pediatric patients with or without ventricular septal defect during anesthesia: in comparison with echocardiography. Paediatr Anaesth. 2014 Jul 21.

42. Vergnaud E1, Vidal C, Montmayeur Verchere J, Taright H, Meyer PG, Carli PA, Orliaguet GA. Noninvasive cardiac output measurement using bioreactance in postoperative pediatric patients. Paediatr Anaesth. 2014 May 12.

43. Fagnoul D, Vincent J-L, Backer DD. Cardiac output measurements using the bioreactance technique in critically ill patients. Crit Care. 2012;16(6):460.

44. Ballestero Y, Urbano J, López-Herce J, Solana MJ, Botrán M, Vinciguerra D, et al. Pulmonary arterial 
thermodilution, femoral arterial thermodilution and bioreactance cardiac output monitoring in a pediatric hemorrhagic hypovolemic shock model. Resuscitation. 2012;83(1):125-9.

45. Gan H, Cannesson M, Chandler J R, Ansermino M J. Predicting fluid responsiveness in children a systematic review, Anaesthesia-Analgesia December 2013;117/6.

46. Pinsky MR, Payen D. Functional haemodynamic monitoring, update in intensive care and emergency medicine 42, p 259 Springer-Verlag Berlin Heidelberg 2005.

47. Theissen M, Theoret J, Liao MM, Kendall J. Inferior vena cava to aorta ratio has limited value for assessing dehydration in young pediatric emergency department patients. Academic Emergency Medicine. April 2012, vol./is. 19/(S181-S182).

48. Jauregui J, Nelson D, Choo E, Stearns B, Levine AC, Liebmann O, et al. The BUDDY (bedside ultrasound to detect dehydration in youth) study. Crit Ultrasound J. 2014;6(1):15. eCollection 2014.

49. Iwamoto Y, Tamai A, Kohno K, et al. Usefulness of respiratory variation of inferior vena cava diameter for estimation of elevated central venous pressure in children with cardiovascular disease. Circ J. 2011;75(5):1209-14.

50. $\mathrm{Ng} \mathrm{L}$, Khine H, Taragin BH. Does bedside sonographic measurement of the inferior vena cava diameter correlate with central venous pressure in the assessment of intravascular volume in children? Pediatr Emerg Care. 2013;29(3):337-41.

51. Pinsky MR, Payen D. Functional hemodynamic monitoring, update in intensive care and emergency medicine. 2005; 42, pp 241, Springer-Verlag Berlin Heidelberg.

52. de Olivera FC, Carcillo J. A beneficial role of central venous oxygen saturation-targeted septic shock management in children: follow the paediatric story not only the adult. Paediatr Crit Care Med. 2014;15(4):380-1.

53. Sankar J, Sankar J, Suresh CP, et al. Early goal-directed therapy in pediatric septic shock: comparison of outcomes "with" and "without" intermittent superior venacaval oxygen saturation monitoring: a prospective cohort study. Paediatr Crit Care Med. 2014;15(4):15767.

54. De Oliveira CF, de Oliveira DS, Gottschald AF, et al. ACCM/PALS haemodynamic support guidelines for paediatric septic shock: an outcomes comparison with and without monitoring central venous oxygen saturation. Intensive Care Med. 2008;34:1065-75.

55. Rivers E, Nguyen B, Havstad S, Ressler J, Muzzin A, Knoblich B, et al. Early goal-directed therapy collaborative group. Early goal-directed therapy in the treatment of severe sepsis and septic shock. N Engl J Med. 2001;345(19):1368-77.

56. Marik PE. Iatrogenic salt water drowning and the hazards of a high central venous pressure. Ann Intensive Care. 2014;4:21.

57. The ARISE Investigators and the ANZICS Clinical Trials Group. Goal-directed resuscitation for patients with early septic shock. N Engl J Med. 2014;371:1496-506. Large multicentre study in adult patients with septic shock, comparing early goal directed therapy to usual care with no mortality difference between the groups. However, both groups have low baseline mortality (18.6 versus $18.8 \%$ ), this is compared to Rivers ${ }^{52}$ with a baseline mortality of $46 \%$.

58. Mohseni-Bod H, Frndova H, Gaitaro R, Holtby H, Bohn D. Evaluation of a new pediatric continuous oximetry catheter. Pediatr Crit Care Med. 2011;12(4):437-41.

59. Spenceley N, Krahn G, Skippen PW, Kissoon N. Evaluation of a pediatric central venous oximetry catheter in critically ill children. Pediatr Crit Care Med. 2010;11(1):26-30.

60. Baulig W, Bettex D, Burki C et al. The PediaSat continuous central SvO2 monitoring system does not reliably indicate state or course of central venous oxygenation, European Journal of Anaesthesiology. August 2010

61. Iodice FG, Ricci Z, Haiberger R, Favia I, Cogo P. Fiberoptic monitoring of central venous oxygen saturation (PediaSat) in small children undergoing cardiac surgery: continuous is not continuous. F1000Research. 2014; vol./is. 3/(23).

62. Tweddell JS, Ghanayem NS, Hoffman G. Pro: NIRS is "standard of care" for postoperative management. Semin Thorac Cardiovasc Surg Pediatr Card Surg Annu. 2010;13(1):44-50.

63. Ghanayem NS, Wernovsky G, Hoffman GM. Nearinfrared spectroscopy as a hemodynamic monitor in critical illness. Pediatr Crit Care Med. 2011;12(4):2732.

64. Chakravarti SB, Mittnacht AJ, Katz JC, Nguyen K, et al. Multisite near-infrared spectroscopy predicts elevated blood lactate level in children after cardiac surgery. J Cardiothorac Vasc Anesth. 2009;23(5):663-7. 